\title{
Improving Scaling and Root Planing Over the Past 40 Years: A Meta-
} Analysis

\author{
Zaugg $\mathbf{B}^{1}$, Sahrmann $\mathbf{P}^{2}$, Roos $\mathbf{M}^{3}$, Attin $\mathbf{T}^{2}$ and Schmidlin $\mathbf{P R}^{2 *}$ \\ ${ }^{1}$ Private Practice, Luzern, Switzerland \\ ${ }^{2}$ Clinic of Preventive Dentistry, Periodontology and Cariology, Center of Dental Medicine, University of Zurich, Switzerland
}

${ }^{3}$ Division of Biostatistics, ISPM, University of Zurich, Hirschengraben 84, 8001 Zurich, Switzerland

\begin{abstract}
Aim: To screen whether or not classical non-surgical periodontal therapy improved over the last four decades and how adjunctive local or systemic measures influenced its clinical outcome.

Methodology: Starting from the year 1970, the entire annual sets of publications of every 5th year of the "Journal of Clinical Periodontology" and the "Journal of Periodontology" were hand searched for articles dealing with nonsurgical periodontal therapy, i.e. scaling and root planing either alone (SRP) or in combination with adjunctive local (SRPloc) or systemic (SRPsyst) treatment. Mean pocket reduction was computed for each of the three treatment modalities. Where applicable, a meta-analysis and a meta-regression as well as linear regression were performed.
\end{abstract}

Results: A total of 52 articles were found. Twenty-six thereof were randomized clinical trials. The meta-analysis revealed a standardized mean difference of pocket reduction of $0.77 \mathrm{~mm}(95 \% \mathrm{Cl}=0.283 ; 1.255)$ and $0.90 \mathrm{~mm}(95 \% \mathrm{Cl}$ $0.210 ; 1.593$ for SRPloc-SRP and SRPsyst-SRP, respectively $(P<0.0001)$. Meta regression showed significantly more mean pocket reduction for SRPloc $(p=0.011)$ and SRPsyst $(p=0.001)$ than for SRP. In addition, a negative correlation between time to re-evaluation and mean pocket reduction could be found $(p=0.015)$. None of the treatment modalities improved over the past 40 years.

Conclusion: Adjunctive local or systemic measures seem to improve the classic non-surgical periodontitis therapy, i.e. scaling and root planing. None of the three analyzed treatment modalities improved over the past 40 years.

Keywords: Periodontitis; Scaling; Debridement; Non-surgical; Review

\section{Introduction}

Periodontitis is a complex infective disease modulated by several host and environmental factors, leading to tissue inflammation and bone resorption $[1,2]$. As a clinical consequence, pocket formation and loss of attachment may occur. Bacteria are considered to be the primary etiological factor [3].

Since the early 1980s effective reduction of supra- and subgingival pathogenic flora by mechanical means i.e. scaling and root planing in combination with a meticulous oral hygiene is considered the gold standard in non-surgical periodontal therapy [4]. However, a complete removal of subgingival deposits and an effective and reliable control of the subgingival vital flora has been shown to be unrealistic and a difficult goal to achieve [5].

In order to overcome these limitations, a large variety of adjunctive measures to improve the outcome of mechanical debridement was tested and published subsequently. Concerning the removal of calculus and biofilm a considerable number of different instruments such as curettes, ultrasonic devices, air scalers, powder jet devices and lasers as well as different protocols have been described [6]. Antibiotics and antiseptics have been introduced as a systemic and local adjunct to mechanical therapy [7]. The use of systemic antibiotics has been widely assessed and contradictorily discussed [8]. Particularly the combination of amoxicillin and metronidazole is warranted in advanced chronic and aggressive periodontitis [9]. On the other hand the use of systemically administered antibiotics is associated with certain risks, notably the development of antibiotic resistance in various bacterial species or allergies and some considerable clinical side-effects like nausea, headaches, diarrhea etc. [10]. In contrast, topical administration of antibiotics and antiseptics supporting mechanical periodontal debridement seems worth consideration [11]. Several antimicrobial chemotherapeutics, varying in concentrations and galenical formulations have been used. They are a quick and potentially less expensive method, and can be applied in the pockets [12]. In most cases, subgingival irrigation with different antiseptic and antibiotic formulations has still not shown clinically significant effectiveness beyond that of conventional mechanical debridement [13]. On the other hand, several local drug delivery devices have become commercially available. The claimed benefit of these more sophisticated systems includes their ability to deliver drugs even within deep pockets at bactericidal or bacteriostatic concentrations for a longer period of time. A systematic review has assessed the local adjunctive anti-infective therapy using a variety of pharmacological agents and found that these agents in a sustained-release vehicle alone could reduce $\mathrm{PD}$ and bleeding on probing (BOP), but equivalent to that achieved by SRP alone [14]. Overall, there is still a lack of information regarding the clinical effectiveness of most of these agents. To sum up adjunctive measures as described above can basically be divided in two main groups: First local and second systemic adjunctive measures. Local measures range from simple irrigation of a periodontal pocket with a disinfectant to considerably more sophisticated therapies such as laser treatment or photodynamic therapy. On the other hand systemic adjunctive treatment is in the main composed of peroral administration

*Corresponding author: Patrick R Schmidlin, Plattenstrasse, Clinic of Preventive Dentistry, Periodontology and Cariology, Center of Dental Medicine, University of Zurich, 11, 8032 Zürich, Switzerland, Tel: +41 4463434 17; Fax: +41 446344308 ; E-mail: patrick.schmidlin@zzm.uzh.ch

Received January 15, 2014; Accepted Janaury 30, 2014; Published February 01, 2014

Citation: Zaugg B, Sahrmann P, Roos M, Attin T, Schmidlin PR (2014) Improving Scaling and Root Planing Over the Past 40 Years: A Meta-Analysis. Dentistry 4: 205. doi:10.4172/2161-1122.1000205

Copyright: @ 2014 Zauug B, et al. This is an open-access article distributed unde the terms of the Creative Commons Attribution License, which permits unrestricted use, distribution, and reproduction in any medium, provided the original author and source are credited. 
of different antibiotics, particularly the combination of amoxicillin and metronidazole.

Looking back on 40 years of research and the persistent struggle to improve decontamination by the mentioned means, one should be allowed to ask an almost heretic question: "With what result?"

Therefore, the aim of the study was to screen, whether or not nonsurgical periodontal therapy improved over the last four decades and how adjunctive local or systemic measures influenced its outcome so far. We hypothesized that technical and pharmaceutical developments in the last four decades and an overall therapeutic learning curve led to more pocket depth reduction.

\section{Materials and Methods}

Starting from the year 1970 the entire annual sets of publications of every 5th year of the "Journal of Clinical Periodontology" as well as the "Journal of Periodontology" were hand searched for articles concerning non-surgical periodontal therapy. Every type of publication exploring the classic non-surgical periodontal therapy, i. e. scaling and root planing either alone or in combination with adjunctive local or systemic treatment such as local drug delivering devices or systemic antibiotics, other drugs or nutritional supplements was included. For inclusion, the study population of the included articles had to suffer from localized or generalized periodontitis. The mean reduction of the clinical pocket (dPD) and its standard deviation (SD) as well as the time span between baseline and the first re-evaluation (ttR) had to be included. As dPD was calculated by subtracting the pocket depth (PD) at re-evaluation from the $\mathrm{PD}$ at baseline. A positive value represented a reduction of the clinical PD. Some publications did not provide $\mathrm{dPD}$ in numeric values. In order to raise the number of includable articles, dPD numeric data was extracted from graphs where possible. For further missing information - for example SD - the approximations from Sachs (Sachs 1991) were applied. Each publication meeting the inclusion criteria was assigned to one of three treatment modalities:

1. SRP: Classic scaling and root planing executed with curettes and/or ultrasonic or air scalers respectively. Any kind of protocol such as full-mouth, quadrant wise or others was included.

2. SRPloc: SRP in combination with adjunctive local treatment such as irrigation of the pockets or application of local drug delivering devices or local laser treatment.

3. SRPsyst: SRP in combination with adjunctive systemic treatment such as antibiotics, other drugs or nutritional supplements.

When performing the meta-analysis, the SRP-groups of respective RCTs served as control-group.

Data were coded in Excel and analyzed with both Medcalc 12.4.0 and SPSS Version 20. For randomized clinical trials meta-analysis together with heterogenity test and appropriate forest plots were provided. Apart from that a meta-regression was considered. It consisted of a multiple linear weighted regression and contained all studies, which have been found. The association between mean pocket reduction and the year of publication was assessed by means of Spearman correlation. Results of statistical analyses with p-values smaller than 0.05 were considered as significant.

\section{Results}

A total of 52 publications were found [15-66]. Twenty-six studies represented randomized controlled clinical trials (RCT; Figures 1 and 2).
Regarding adjunctive local (SRPloc) therapy, irrigation of the pockets with disinfectants, application of local drug delivering devices [17-22] or local laser treatment [23-26] were identified. Pocket irrigation and mouth rinses in most of the studies were performed with chlorhexidine [27-29,66]. Another study used povidone iodine instead [67].

Regarding systemic (SRPsyst) treatment, amoxicillin and metronidazole or metronidazole alone was used in most studies [3338]. Several studies tested doxycycline in subantimicrobial $[39,40,68]$ or antibacterial doses [42]. Two studies assayed azithromycin $[43,44]$ and one further publication evaluated clindamycin [45]. Other drugs like atorvastatin [31] or nutritional supplements such as vitamin $C$, omega-3 fatty acids and low-dose aspirin [15,32] were also screened.

The meta-analysis of the RCTs revealed that combining SRP with adjunctive local or systemic measures respectively provided more mean pocket reduction than the classic treatment i.e. SRP alone (Figures 1 and 2), when the random effects model had been considered. When comparing SRP with SRPloc, the additional standardized mean pocket

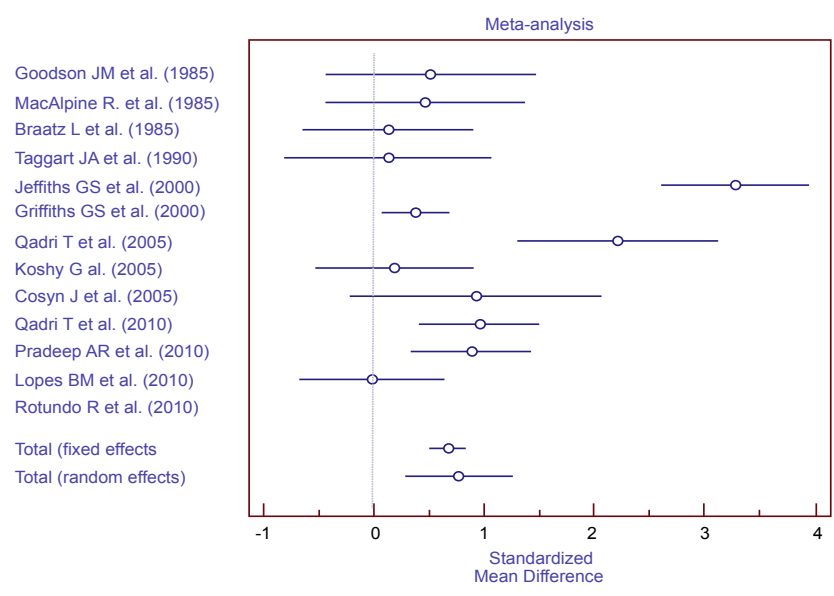

Figure 1: Forest plot: SRPloc provided significantly more reduction of the clinical pocket than SRP. The standardized mean difference of mean pocket reduction (SRPloc - SRP) was $0.77 \mathrm{~mm}$ with corresponding $95 \% \mathrm{Cl}$ between 0.283 and 1.255 under consideration of random effects model $(P<0.0001)$.

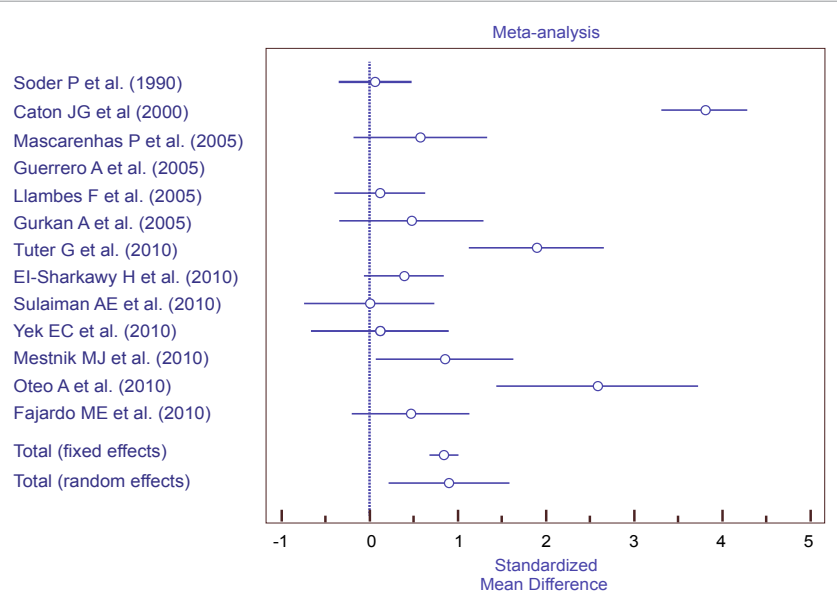

Figure 2: Forest plot: SRPsyst provided significantly more reduction of the clinical pocket than SRP. The standardized mean difference of mean pocket reduction (SRPsyst - SRP) was $0.90 \mathrm{~mm}$ with corresponding $95 \% \mathrm{Cl}$ between 0.210 and 1.593 under consideration of random effects model $(P<0.0001)$. 
reduction of local treatment was $0.77 \mathrm{~mm}$, whereas when comparing the classic (SRP) with the adjunctive systemic treatment (SRPsyst) the additional standardized mean pocket reduction accounted for 0.90 $\mathrm{mm}$. For both comparisons, the zero value was not contained in the 95\% CI which implied, that these results were highly significant.

The meta-regression of all 52 studies showed that both predictors, type of treatment $(\mathrm{p}<0.001)$ as well as time to re-evaluation $(\mathrm{p}=0.015)$ had an influence on mean pocket reduction (Figure 3 ). In conformity with the meta-analysis, SRP achieved minor results than SRPloc and SRPsyst respectively when the calculation was adjusted for time to reevaluation. In addition, there was no statistically significant difference between SRPloc and SRPsyst ( $\mathrm{p}=0.566)$.

The time span between baseline and re-evaluation (ttR) differed between 1.5 and 12 months and had a significant influence on the outcome of the studies under investigation. The longer the $t \mathrm{tR}$, the

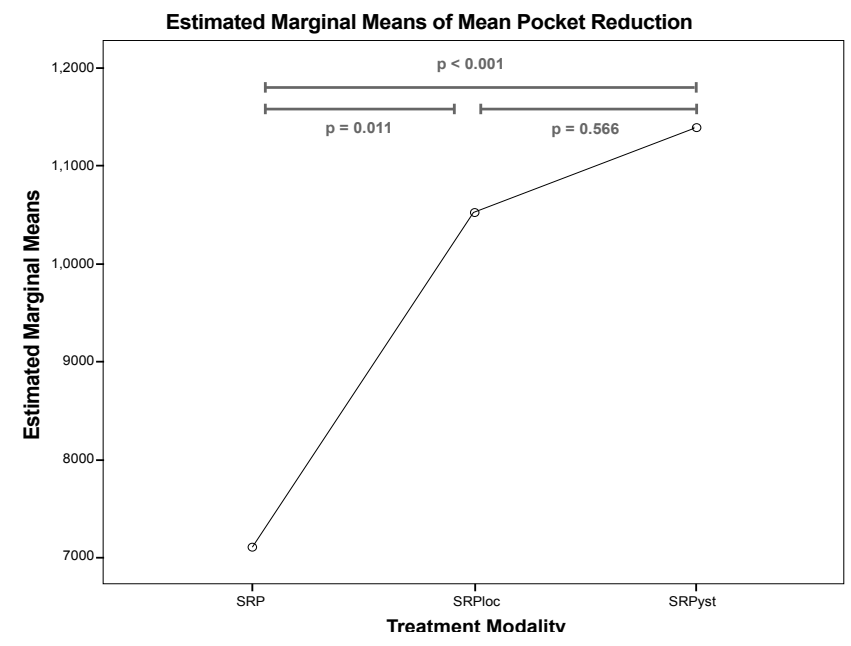

Figure 3: Estimated marginal means of mean pocket reduction in the mode adjusted for time to reevaluation for the three different treatment modalities. SRPloc as well as SRPsyst provided significantly more reduction of the clinical pocket than SRP.

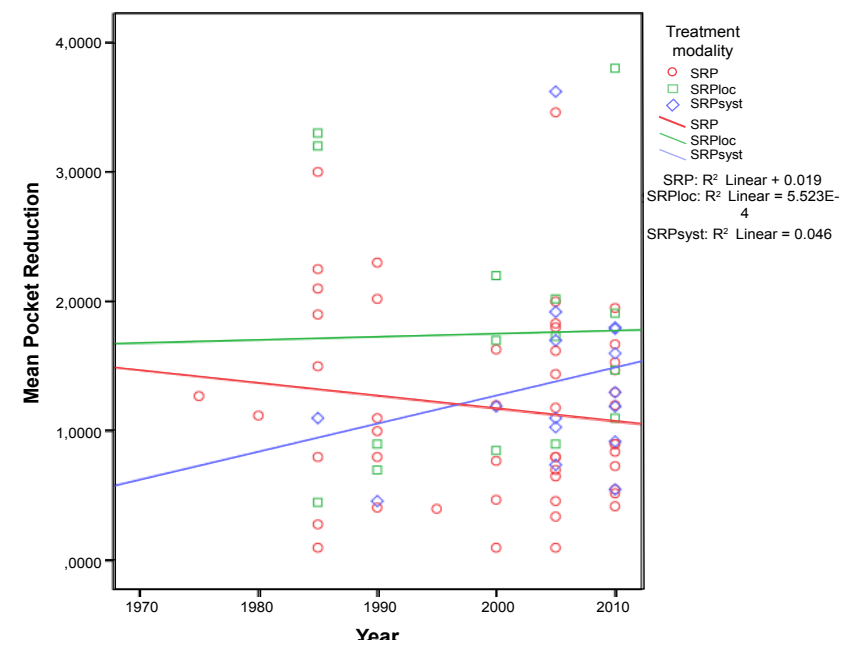

Figure 4: Linear regression lines for mean pocket reduction on the year of publication for the three different treatment modalities. The Spearman correlation together with coefficients of determination couldn't reveal any improvement in any of the searched treatment modalities over the past 40 years $(p>0.45)$. smaller was the achieved mean pocket reduction (beta $=-0.043, \mathrm{p}=0.015$, 95\% CI (beta) $=(-0.078,-0.009))$.

Spearman correlation looking at the three treatment modalities separately, revealed no significance (Figure 4), i.e. none of them improved over the past 40 years (SRP $\mathrm{p}=0.548$; SRPloc $\mathrm{p}=0.565$; SRPsyst $\mathrm{p}=0.450)$. Moreover, - when pooling all treatment modalitiesthe probing pocket depth reduction after non-surgical periodontal treatment did not improve over time neither $(\mathrm{p}=0.913)$.

\section{Discussion}

Within the limitations of this study it could be shown by metaanalysis as well as meta-regression that the introduction of adjunctive local or systemic treatment had a beneficial effect on classic scaling and root planning indeed.

Considering the fact that only a selection of volumes of just two journals were searched as well as the fact that treatment options have been reduced to only three treatment modalities - these statements cannot be conclusive nor definitive.

Most evidence seems to exist for the beneficial effect of adjunctive systemic antibiotics and particularly for the combination of amoxicillin and metronidazole to non-surgical periodontal therapy [8,9,69-72]. It has to be underlined that the systemic administration of antibiotics is only recommended in combination with mechanical debridement of the root surfaces i.e. scaling and root planning [8].

Among the included studies in the present meta-analysis, primarily tetracycline, metronidazole and chlorhexidine were used as locally administered antimicrobials. Another systematic review corroborated our findings and showed that the most positive results occurred for exactly these substances and that their local administration generally reduced PD levels significantly [73]. However, when compared to SRP alone, the benefit in this study seemed to be rather small (0.1-0.5 mm).

We only analyzed data from studies reporting classical SRP. In the last few years, the significance of laser in non-surgical periodontal therapy either alone or as an adjunct to SRP has been widely discussed and numerous reviews of the literature have been published. Most authors concluded that there is still insufficient evidence to suggest that any specific wavelength of laser or treatment protocol is superior to the traditional modalities of therapy and that further research is needed [74-76].

Observing the mean pocket reduction over time, it seems as if there was no substantial improvement in non-surgical periodontal therapy over the past 40 years neither when looking at the three assessed treatment modalities separately nor when combining all the different treatment approaches to one group. However, the heterogeneity of the included studies was remarkable. Some publications dealt only with the deepest site in every patient, while others calculated with full mouth PD $[54,77]$. In that way "mean pocket reduction" could simply be the wrong parameter to base such a statement on.

Finally we could show that time span between baseline and reevaluation (ttR) stands in inverse ratio to dPD. This can easily be explained by the fact that the re-establishment of a disease-associated, subgingival microbiota may take several months [78]. Furthermore, with growing distance to the initial therapy, the role of supportive periodontal treatment in maintaining successful results becomes more and more important [79].

Two studies assessing local antibiotic/antiseptic treatment (Figure 1) $[20,24]$ as well as three studies with a systemic antimicrobial approach 
(Figure 2) $[40,41,43]$ showed relatively high values for standardized mean differences in pocket reduction. This can be explained as follows: some of these studies included high numbers (up to 190) of participants [68] and/or had a small spread i.e. standard deviation (SD) of their data [20], which gives them a higher weight in the meta-analysis. On the other hand, study design plays a crucial role. For example, one study included only four sites per patient with probing depths between 5 and $8 \mathrm{~mm}$ [20]. Other studies just referred to single-rooted teeth [40] or sites with PD deeper than $3 \mathrm{~mm}$ [41], which of course also results in a higher mean pocket reduction compared to publications who dealt with full-mouth measurements.

\section{Conclusion}

It can be concluded - despite some methodological drawbacks of this screening study - that the combination of scaling and root planing and adjunctive local or systemic treatment provides more mean pocket reduction than SRP alone, which is corroborated by the modern literature. However, in contrast to the hypothesis, there is no trend that non-surgical periodontal therapy significantly improved over the last 40 years with regard to better pocket depth reduction potential-neither in general nor when looking at any of the three assessed treatment modalities separately.

\section{References}

1. Page RC, Kornman KS (1997) The pathogenesis of human periodontitis: an introduction. Periodontol 2000 14: 9-11.

2. Kornman KS, Page RC, Tonetti MS (1997) The host response to the microbial challenge in periodontitis: assembling the players. Periodontol 2000 14: 33-53.

3. Socransky SS, Haffajee AD (2005) Periodontal microbial ecology. Periodontol 2000 38: 135-187.

4. Suvan JE (2005) Effectiveness of mechanical nonsurgical pocket therapy. Periodontol 2000 37: 48-71

5. Caffesse RG, Sweeney PL, Smith BA (1986) Scaling and root planing with and without periodontal flap surgery. J Clin Periodontol 13: 205-210.

6. Drisko CL, Cochran DL, Blieden T, Bouwsma OJ, Cohen RE et al. (2000) Position paper: sonic and ultrasonic scalers in periodontics. Research, Science and Therapy Committee of the American Academy of Periodontology. J Periodontol 71: 1792-1801.

7. Salvi GE, Mombelli A, Mayfield L, Rutar A, Suvan J et al. (2002) Local antimicrobial therapy after initial periodontal treatment. J Clin Periodontol 29: 540-550.

8. Heitz-Mayfield LJ (2009) Systemic antibiotics in periodontal therapy. Aust Dent J 54: S96-101.

9. Zandbergen D, Slot DE, Cobb CM, Van der Weijden FA (2013) The clinical effect of scaling and root planing and the concomitant administration of systemic amoxicillin and metronidazole: a systematic review. J Periodontol 84: 332-351.

10. Ciancio SG (2000) Antiseptics and antibiotics as chemotherapeutic agents for periodontitis management. Compend Contin Educ Dent 21: 59-62.

11. Mombelli A, Samaranayake LP (2004) Topical and systemic antibiotics in the management of periodontal diseases. Int Dent J 54: 3-14.

12. Vandekerckhove BN, Quirynen M, van Steenberghe D (1998) The use of locally delivered minocycline in the treatment of chronic periodontitis. A review of the literature. J Clin Periodontol 25: 964-968.

13. Greenstein G (2005) Position paper: The role of supra- and subgingival irrigation in the treatment of periodontal diseases. J Periodontol 76: 2015-2027.

14. Hanes PJ, Purvis JP (2003) Local anti-infective therapy: pharmacological agents. A systematic review. Ann Periodontol 8: 79-98.

15. Abou Sulaiman AE, Shehadeh RM (2010) Assessment of total antioxidant capacity and the use of vitamin $\mathrm{C}$ in the treatment of non-smokers with chronic periodontitis. J Periodontol 81: 1547-1554.

16. Apatzidou DA, Riggio MP, Kinane DF (2005) Impact of smoking on the clinical, microbiological and immunological parameters of adult patients with periodontitis. J Clin Periodontol 32: 973-983.

17. Griffiths GS, Smart GJ, Bulman JS, Weiss G, Shrowder J, et al. (2000) Comparison of clinical outcomes following treatment of chronic adult periodontitis with subgingival scaling or subgingival scaling plus metronidazole gel. J Clin Periodontol 27: 910-917.

18. Goodson JM, Hogan PE, Dunham SL (1985) Clinical responses following periodontal treatment by local drug delivery. J Periodontol 56: 81-87.

19. Pradeep AR, Thorat MS (2010) Clinical effect of subgingivally delivered simvastatin in the treatment of patients with chronic periodontitis: a randomized clinical trial. J Periodontol 81: 214-222.

20. Jeffcoat MK, et al. (2000) Use of a biodegradable chlorhexidine chip in the treatment of adult periodontitis: clinical and radiographic findings. J Periodontol 71: 256-262.

21. Eckles TA, Reinhardt RA, Dyer JK, Tussing GJ, Szydlowski WM, et al. (1990) Intracrevicular application of tetracycline in white petrolatum for the treatment of periodontal disease. J Clin Periodontol 17: 454-462.

22. Cosyn J, Wyn I, De Rouck T, Sabzevar MM (2005) A chlorhexidine varnish implemented treatment strategy for chronic periodontitis: short-term clinical observations. J Clin Periodontol 32: 750-756.

23. Qadri T, Poddani P, Javed F, Tuner J, Gustafsson A (2010) A short-term evaluation of $\mathrm{Nd}$ :YAG laser as an adjunct to scaling and root planing in the treatment of periodontal inflammation. J Periodontol 81: 1161-1166.

24. Qadri T, Miranda L, Tuner J, Gustafsson A (2005) The short-term effects of lowlevel lasers as adjunct therapy in the treatment of periodontal inflammation. $J$ Clin Periodontol 32: 714-719.

25. Lopes BM, Theodoro LH, Melo RF, Thompson GM, Marcantonio RA (2010) Clinical and microbiologic follow-up evaluations after non-surgical periodontal treatment with erbium: YAG laser and scaling and root planing. J Periodontol 81: 682-691.

26. Rotundo R, Nieri M, Cairo F, Franceschi D, Mervelt J, et al. (2010) Lack of adjunctive benefit of Er:YAG laser in non-surgical periodontal treatment: a randomized split-mouth clinical trial. J Clin Periodontol 37: 526-533.

27. Quirynen M, Mongardini C, de Soete M, Pauwels M, Coucke W, et al (2000) The role of chlorhexidine in the one-stage full-mouth disinfection treatment of patients with advanced adult periodontitis. Long-term clinical and microbiological observations. J Clin Periodontol 27: 578-589.

28. MacAlpine R, Magnusson I, Kiger R, Crigger M, Garrett S, et al. (1985) Antimicrobial irrigation of deep pockets to supplement oral hygiene instruction and root debridement. I. Bi-weekly irrigation. J Clin Periodontol 12: 568-577.

29. Braatz L, Garrett S, Claffey N, Egelberg J (1985) Antimicrobial irrigation of deep pockets to supplement non-surgical periodontal therapy. II. Daily irrigation. J Clin Periodontol 12: 630-638.

30. Koshy G, Kawashima Y, Kiji M, Nitta H, Umeda M, et al. (2005) Effects of single-visit full-mouth ultrasonic debridement versus quadrant-wise ultrasonic debridement. J Clin Periodontol 32: 734-743.

31. Fajardo ME, Rocha ML, Sanchez-Marin FJ, Espinosa-Chavez EJ (2010) Effect of atorvastatin on chronic periodontitis: a randomized pilot study. J Clin Periodontol 37: 1016-1022.

32. El-Sharkawy H, Aboelsaad N, Eliwa M, Darweesh M, Alshahat M, et al. (2010) Adjunctive treatment of chronic periodontitis with daily dietary supplementation with omega-3 Fatty acids and low-dose aspirin. J Periodontol 81: 1635-1643.

33. Yek EC, Cintan S, Topcuoglu N, Kulekci G, Issever H, et al. (2010) Efficacy of amoxicillin and metronidazole combination for the management of generalized aggressive periodontitis. J Periodontol 81: 964-974.

34. Guerrero A, Griffiths GS, Nibali L, Suvan J, Moles DR, et al. (2005) Adjunctive benefits of systemic amoxicillin and metronidazole in non-surgical treatment of generalized aggressive periodontitis: a randomized placebo-controlled clinical trial. J Clin Periodontol 32: 1096-1107.

35. Mestnik MJ, Feres M, Figueiredo LC, Duarte PM, Lira EA, et al. (2010) Shortterm benefits of the adjunctive use of metronidazole plus amoxicillin in the microbial profile and in the clinical parameters of subjects with generalized aggressive periodontitis. J Clin Periodontol 37: 353-365.

36. Sigusch BW, Guntsch A, Pfitzner A, Glockmann E (2005) Enhanced root planing and systemic metronidazole administration improve clinical and microbiological outcomes in a two-step treatment procedure. J Periodontol 76: 991-997. 
37. Sigusch BW, Pfitzner A, Nietzsch T, Glockmann E (2005) Periodontal dressing (Vocopac) influences outcomes in a two-step treatment procedure. J Clin Periodontol 32: 401-405

38. Soder PO, Frithiof L, Wikner S, Wouters F, Engström PE, et al. (1990) The effect of systemic metronidazole after non-surgical treatment in moderate and advanced periodontitis in young adults. J Periodontol 61: 281-288.

39. Gurkan A, Cinarcik S, Huseyinov A (2005) Adjunctive subantimicrobial dose doxycycline: effect on clinical parameters and gingival crevicular fluid transforming growth factor-beta levels in severe, generalized chronic periodontitis. J Clin Periodontol 32: 244-253.

40. Tuter G, Serdar M, Kurtiş B, Walker SG, Atak A, et al. (2010) Effects of scaling and root planing and subantimicrobial dose doxycycline on gingival crevicular fluid levels of matrix metalloproteinase-8, -13 and serum levels of HsCRP in patients with chronic periodontitis. J Periodontol 81: 1132-1139.

41. Caton JG, Ciancio SG, Blieden TM, Bradshaw M, Crout RJ, et al. (2000) Treatment with subantimicrobial dose doxycycline improves the efficacy of scaling and root planing in patients with adult periodontitis. J Periodontol 71: $521-532$

42. Llambes F, Silvestre FJ, Hernandez-Mijares A, Guiha R, Caffesse R (2005) Effect of non-surgical periodontal treatment with or without doxycycline on the periodontium of type 1 diabetic patients. J Clin Periodontol 32: 915-920.

43. Oteo A, Herrera D, Figuero E, O'Connor A, González I, et al. (2010)Azithromycin as an adjunct to scaling and root planing in the treatment of Porphyromonas gingivalis-associated periodontitis: a pilot study. J Clin Periodontol 37: 10051015.

44. Mascarenhas P, Gapski R, Al-Shammari K, Hill R, Soehren S, et al. (2005) Clinical response of azithromycin as an adjunct to non-surgical periodontal therapy in smokers. J Periodontol 76: 426-436.

45. Gordon J, Walker C, Lamster I, West T, Socransky S, et al. (1995) Efficacy of clindamycin hydrochloride in refractory periodontitis. 12-month results. $J$ Periodontol 56: 75-80.

46. Badersten A, Nilveus R, Egelberg J (1985) Effect of non-surgical periodontal therapy (IV). Operator variability. J Clin Periodontol 12: 190-200.

47. Brochut PF, Marin I, Baehni P, Mombelli A (2005) Predictive value of clinica and microbiological parameters for the treatment outcome of scaling and root planing. J Clin Periodontol 32: 695-701.

48. Chapple IL, Walmsley AD, Saxby MS, Moscrop H (1995) Effect of instrument power setting during ultrasonic scaling upon treatment outcome. J Periodontol 66: $756-760$

49. Claffey N, Magnusson I, Crigger M, Garrett S, Kiger RD, et al. (1985) Subgingival spirochete and leukocyte counts as indicators of response to therapy. J Clin Periodontol 12: 639-647.

50. Colombo AP, Teles RP, Torres MC, Rosalém W, Mendes MC, et al. (2005) Effects of non-surgical mechanical therapy on the subgingival microbiota of Brazilians with untreated chronic periodontitis: 9-month results. J Periodontol 76: 778-784

51. Cugini MA, Haffajee AD, Smith C, Kent RLJ, Socransky SS (2000) The effect of scaling and root planing on the clinical and microbiological parameters of periodontal diseases: 12-month results. J Clin Periodontol 27: 30-36.

52. Darby IB, Hodge PJ, Riggio MP, Kinane DF (2005) Clinical and microbiological effect of scaling and root planing in smoker and non-smoker chronic and aggressive periodontitis patients. J Clin Periodontol 32: 200-206.

53. Dubrez B, Graf JM, Vuagnat P, Cimasoni G (1990) Increase of interproximal bone density after subgingival instrumentation: a quantitative radiographical study. J Periodontol 61: 725-731.

54. Kornman KS, Robertson PB (1985) Clinical and microbiological evaluation of therapy for juvenile periodontitis. J Periodontol 56: 443-446.

55. Lindhe J, Nyman S (1985) Scaling and granulation tissue removal in periodontal therapy. J Clin Periodontol 12: 374-388.

56. Morrison EC, Ramfjord SP, Hill RW (1980) Short-term effects of initial, nonsurgical periodontal treatment (hygienic phase). J Clin Periodontol 7: 199211

57. Pawlowski AP, Chen A, Hacker BM, Mancl LA, Page RC, et al. (2005) Clinical effects of scaling and root planing on untreated teeth. $\mathrm{J}$ Clin Periodontol 32 : $21-28$
58. Ramfjord SP, Knowles JW, Nissle RR, Burgett FG, Shick RA (1975) Results following three modalities of periodontal therapy. J Periodontol 46: 522-526.

59. Renvert S, Nilveus R, Dahlen G, Slots J, Egelberg J (1990) 5-year follow up of periodontal intraosseous defects treated by root planing or flap surgery. J Clin Periodontol 17: 356-363.

60. Renvert S, Wikstrom M, Dahlen G, Slots J, Egelberg J (1990) On the inability of root debridement and periodontal surgery to eliminate Actinobacillus actinomycetemcomitans from periodontal pockets. J Clin Periodontol 17: 351 355

61. Saito A, Hosaka Y, Kikuchi M, Akamatsu M, Fukaya C, Matsumoto S, et al. (2010) Effect of initial periodontal therapy on oral health-related quality of life in patients with periodontitis in Japan. J Periodontol 81: 1001-1009.

62. Vettore M, Quintanilha RS, Monteiro da Silva AM, Lamarca GA, Leao AT (2005) The influence of stress and anxiety on the response of non-surgical periodontal treatment. J Clin Periodontol 32: 1226-1235.

63. Wennstrom JL, Tomasi C, Bertelle A, Dellasega E (2005) Full-mouth ultrasonic debridement versus quadrant scaling and root planing as an initial approach in the treatment of chronic periodontitis. J Clin Periodontol 32: 851-859.

64. Westfelt E, Bragd L, Socransky SS, Haffajee AD, Nyman S, et al. (1985) Improved periodontal conditions following therapy. J Clin Periodontol 12: 283 293.

65. Zijnge V, Meijer HF, Lie MA, Tromp JA, Degener JE, et al. (2010) The recolonization hypothesis in a full-mouth or multiple-session treatment protocol: a blinded, randomized clinical trial. J Clin Periodontol 37: 518-525.

66. Taggart JA, Palmer RM, Wilson RF (1990) A clinical and microbiological comparison of the effects of water and $0.02 \%$ chlorhexidine as coolants during ultrasonic scaling and root planing. J Clin Periodontol 17: 32-37.

67. 67. Koshy G, Corbet EF, Ishikawa I (2004) A full-mouth disinfection approach to nonsurgical periodontal therapy--prevention of reinfection from bacterial reservoirs. Periodontol 2000 36: 166-178.

68. Caton J, Greenstein G, Polson AM (1981) Depth of periodontal probe penetration related to clinical and histologic signs of gingival inflammation. $J$ Periodontol 52: 626-629.

69. Krayer JW, Leite RS, Kirkwood KL (2010) Non-surgical chemotherapeutic treatment strategies for the management of periodontal diseases. Dent Clin North Am 54: 13-33.

70. Mombelli A (2012) Antimicrobial advances in treating periodontal diseases Front Oral Biol 15: 133-148.

71. Mombelli A, Decaillet F, Almaghlouth A, Wick P, Cionca N (2011) Efficient minimally invasive periodontal therapy. An evidence based treatment concept. Schweiz Monatsschr Zahnmed 121: 145-157.

72. Sanz M, Teughels W (2008) Innovations in non-surgical periodontal therapy: Consensus Report of the Sixth European Workshop on Periodontology. J Clin Periodontol 35: 3-7.

73. Bonito AJ, Lux L, Lohr KN (2005) Impact of local adjuncts to scaling and roo planing in periodontal disease therapy: a systematic review. J Periodontol 76 1227-1236.

74. Schwarz F, Aoki A, Becker J, Sculean A (2008) Laser application in non-surgical periodontal therapy: a systematic review. J Clin Periodontol 35: 29-44.

75. Aoki A, Mizutani K, Takasaki AA, Sasaki KM, Nagai S, et al. (2008) Current status of clinical laser applications in periodontal therapy. Gen Dent 56: 674687.

76. Karlsson MR, Diogo Lofgren Cl, Jansson HM (2008) The effect of laser therapy as an adjunct to non-surgical periodontal treatment in subjects with chronic periodontitis: a systematic review. J Periodontol 79: 2021-2028.

77. Morris JF, Sewell DL (1994) Necrotizing pneumonia caused by mixed infection with Actinobacillus actinomycetemcomitans and Actinomyces israelii: case report and review. Clin Infect Dis 18: 450-452.

78. Magnusson I, Lindhe J, Yoneyama T, Liljenberg B (1984) Recolonization of a subgingival microbiota following scaling in deep pockets. J Clin Periodontol 11 193-207.

79. Renvert S, Persson GR (2004) Supportive periodontal therapy. Periodontol 2000 36: 179-195 